\title{
Opinião
}

\section{A CIÊNCIA, A TECNOLOGIA, A INFELICIDADE E O ESTRESSE HUMANO NO TRABALHO}

\author{
Barnardo Melgaço da Silva (1)
}

\begin{abstract}
A pobreza, enquanto condição humana, atingiu proporções catastróficas, no século XX, afetando a vasta maioria da sociedade contemporânea. Mas não é apenas a escala da pobreza corrente que a torna uma condição única e decisiva para a paz e atmosfera de bem-estar das futuras gerações. É também o fato de que o crescimento dessa miséria humana está acontecendo na presença de uma rápida expansão da riqueza humana. Os ricos ficam mais ricos e os pobres, mais pobres, tudo numa era de imenso poder científico-tecnológico. (MOURA, 1995. s.p.)
\end{abstract}

O homem quer como ser social quer como sujeito potencialmente criativo e criador é tanto agente quanto o paciente das descobertas-transformações inerentes às suas próprias idealizaçõescriações. No afã de aumentar seus horizontes de conhecimento e de restabelecer o equilíbrio de suas necessidades básicas, ele busca novos parâmetros de conquistas e realizações conduzindo gradativamente o grupo social a uma redefinição de seus papéis sociais e existenciais.

O indivíduo, a família, o mercado e a sociedade são assim os quatro sistemas imediatamente afetados nessa conjunção de forças transformadoras que mudam os costumes, os hábitos e as atitudes produzindo dessa maneira novas estruturas e novas formas de organizações participativas na vida comunitária.

O ser humano em sua forma moderna de sobrevivência criou nos últimos séculos três grandes espaços organizados, interdependentes e padronizados que são: a sociedade, a empresa e a ciência. De um lado a sociedade se comporta como agente de consumo "forçando" a empresa somente a produzir o que a sociedade deseja e necessita. E por outro lado, ela se comporta como um mercado-agente de produção "forçando" a ciência a enveredar por novos caminhos do conhecimento, face as dificuldades inerentes a carência de recursos para as suas necessidades básicas de sobrevivência. É dentro desse contexto que as empresas e os mercados procuram se organizar, se estruturar e sobreviver competindo entre si para o bem comum da sociedade, da família e do indivíduo.

A empresa pressionada de um lado pela busca do lucro, pelas necessidades da sociedade, pelas pressões dos mercados e por outro lado pela liberdade de inovações tecnológicas da ciência, vem 
buscando transcender seu próprio modo de criar e produzir objetos-produtos de interesse social. Além disso, no contexto desse espaço da empresa outros agentes internos também atuam criando circunstâncias novas para a viabilidade sócio/técnica da organização como um todo. No plano da relação pessoa/grupo os valores humanos tem uma importância vital para o sucesso do empreendimento no contexto social da empresa. E no plano da relação organização/tecnologia a filosofia de administração é de fundamental importância para o sucesso técnico/econômico.

Nesse sentido, a organização do trabalho em grupo se torna um grande complexo social e tecnológico voltado para os objetivos econômicos e/ou políticos. A empresa torna-se o grande palco dos ajustes/desajustes nas ações/reações dos processos psicossomáticos do homem e automáticos dos processos tecnológicos. Nesse espaço da empresa operam-se os movimentos de equilíbrio organizacional da relação trabalho/tecnologia e de equilíbrio orgânico da relação psique/físico (numa dimensão e em outra dimensão na relação ego/self) do homem. Na interseção dos dois domínios (organização-organismo) as variáveis humanas são "medidas" e ajustadas em relação às variáveis tecnológicas. Pois, o que se pretende é o ganho de valor econômico através da eficiência do trabalho no contexto da força produtiva humana viabilizada pela tecnologia, com o objetivo social de oferecer a sociedade os produtos em condições tais que sejam suficientes em qualidade e quantidade.

Assim sendo, a pressão de um lado das necessidades sociais e por outro lado a força do ganho do capital produtivo e do poder de nichos financeiros fizeram com que essa tecnologia [da informação e do conhecimento] recém desenvolvida fosse aperfeiçoada acelerando cada vez mais o ritmo e a velocidade do progresso tecnológico e da internacionalização do capital. Em conseqüência o consumo aumentou velozmente. E dessa forma o volume de informações e bens também precisaram crescer face a demanda e a pressão sócio/técnica dos agentes de produção e consumo.

Inevitavelmente, no espaço da empresa, o ciclo de desenvolvimento de produto precisou ser reduzido drasticamente. Essa redução do ciclo de desenvolvimento, por sua vez, exigiu das empresas uma nova forma de planejamento e programação das informações e dos recursos materiais e humanos. Nesse sentido, o objetivo tem sido sem dúvida de estabelecer um ritmo, se possível, único (padrão) no espaço dinâmico da empresa. Desta forma, podemos inferir que quanto maior o ritmo, menor é o ciclo e mais abrangente deve ser a visão e a regulação da velocidade do sistema produtivo-econômico (existe uma relação entre a freqüência e a velocidade).

Manter um "único" (padrão de) ritmo significa definir claramente as velocidades das interfaces humanas e tecnológicas de acordo com as estratégias de mercado, de produto e de produção. Um eficiente sistema de comunicação entre os níveis estratégico, tático e operacional é de fundamental importância para a sincronização entre os ritmos das necessidades e as velocidades de respostas dos recursos materiais/tecnológicos e humanos disponíveis. 
A atual tendência dos mercados de trabalho é reduzir o número de trabalhadores "centrais" e empregar cada vez mais uma força de trabalho que entra facilmente e é demitida sem custos quando as coisas ficam ruins.

A informática, cria a ilusão, de que poderemos alcançar o patamar de desenvolvimento dos países desenvolvidos sem que para isso se equipe as universidades com bons professores e se reestruture a educação básica com metodologias inovadoras. Mas, como essa mudança está atrelada ao poder econômico em suprir não só essa deficiência como também erradicar a fome e a miséria acumulada nas calçadas e debaixo das marquises dos prédios luxuosos, a solução vai depender de uma independência econômica dos países menos desenvolvidos em relação aos países mais desenvolvidos.

Nesse contexto, podemos constatar um círculo vicioso entre a ciência e o poder econômico. O poder econômico serve a ciência e vice-versa. Quem já é rico tende a ser mais rico e independente. E quem já é pobre tende a ser mais pobre e dependente. O primeiro (o rico) se torna um servidor de tecnologia e o segundo (pobre) se torna por sua vez um cliente de tecnologia. Essa relação tende a permanecer "ad infinitum" porque em essência esta relação está sustentada na lógica da competição econômica (valores materiais) e não na cooperação de valores humanos (valores espirituais).

A igualdade com independência pertence a prática dos princípios éticos humanos na esfera de relações humanas em todos ambientes, inclusive, científico-tecnológico.

O trabalho é um esforço em que se emprega energia, consciência e a própria vida de quem o realiza. Ele é energia e por isso consome calorias. É também consciência porque utiliza-se de meios lógicos mentais-racionais para ordená-lo, controlá-lo e organizá-lo. E por último ele é vida porque seu destino final é para a manutenção da sobrevivência social (de um grupo, nação ou do planeta) ou para a existência pessoal.

O valor do trabalho deve, portanto, ser avaliado em função do quanto o seu conteúdo ajuda ou prejudica, dignifica ou danifica ou, equilibra ou desequilibra à natureza humana e o seu meio ambiente. Não se deve avaliar o trabalho apenas pelo seu conteúdo quantitativo utilitário, mas principalmente pelo seu conteúdo qualitativo essencial.

Nesse sentido, pode-se diferenciar dois processos que qualificam o conteúdo do trabalho [nas suas duas dimensões: objetiva e interior]. O primeiro processo produz valores necessários à sobrevivência do indivíduo na sua relação com o seu mundo social e ecológico. O segundo processo produz valores essenciais à existência da pessoa na sua relação com o seu Criador e com os mundos social-ecológico e ontológico. Nesse contexto, a pessoa humana transcende ontologicamente o indivíduo humano.

A relação entre pessoa e indivíduo estabelece uma ordem hierárquica no processo evolutivo no interior do mundo humano. Em outras palavras, essa ordem está associada a um princípio de transcendência inerente à condição humana: ser pessoa. A condição humana se divide, portanto, em se realizar como indivíduo e se realizar como pessoa. O indivíduo inserido no mundo social é chamado a 
encontrar sentido no trabalho socialmente necessário. E a pessoa inserida no mundo sagrado é chamado a encontrar sentido no trabalho essencial ou disciplina pessoalmente imprescindível (os hindus chamam de "sadhana" (disciplina para o progresso espiritual)). São duas naturezas de trabalho e, portanto, de energia, de consciência e de vida. E que se complementam no interior do mundo humano. A harmonia entre essas duas naturezas de trabalho vai depender da cultura, da educação e da civilização em que o ser nasceu, cresceu e se ordenou (se disciplinou ou aprendeu). Ou, vai se realizar através de uma decisão proveniente de uma radical higiene da alma, ou seja, através de uma purificação como resultado de uma profunda crise existencial.

A crença do trabalho produtivo como suporte para uma vida existencial livre e plena de realizações (de consumo utilitário) foi sutilmente incutida na consciência dos indivíduos. Pois, sem essa crença o trabalho produtivo não alcançaria o seu status atual. O caminho para essa inserção foi sem dúvida o questionamento da vida religiosa restritiva e seus valores de salvação da vida humana. $\mathrm{O}$ homem carente e desejoso de encontrar plenamente seus valores de felicidade e de liberdade, se deixou educar docemente pela propaganda do sacrifício produtivo: o "trabalho [técnico] dignifica o homem" e o "tempo é dinheiro". Uma vez tendo sido introduzida uma distorção de impacto moral e social, o esforço seguinte foi semear a nova matriz de realizações mercantil e exploradora do ser e da natureza.

A felicidade e a liberdade de realização da vida ficou subjugada ao domínio da experiência lógica mecanizada. O desequilíbrio humano foi flagrante, mas atenuado pela lógica da explicação da vida combativa (senhor $\mathrm{x}$ escravo ou vencedor $\mathrm{x}$ vencido) do ser humano em outras civilizações mais antigas. O exemplo humano de salvação e libertação (Jesus Cristo) passou a ser uma peça de adoração e de respeito sem contudo conseguir romper com os padrões de conduta do ser produtivo em seu caminho de desenvolvimento material na modernidade de costumes, hábitos e consumo.

A busca da felicidade e, portanto, da liberdade espontânea sucumbiu diante da não cumprida promessa de realização econômica para todos. Foi em cima da promessa de uma felicidade livre, ou de uma liberdade feliz, que as sociedades modernas procuraram criar raizes e reorientar o sentido da vida humana. Pois, indistintamente todos querem de alguma forma realizar um projeto de vida onde a felicidade é a sua meta final de liberdade de realização. Essa meta é a própria busca do homem em relação ao Amor do Criador, por isso mesmo qualquer propaganda sutilmente bem feita sempre vai encontrar espaço para evoluir no seio de um mundo carente desse Amor maior do Criador.

No contexto da vida social as atividades produtivas não deveriam estar isoladas das atividades da vida existencial/espiritual. Mas, a história é outra. A atividade produtiva se isolou a partir do século XVI produzindo um grande abismo no interior do próprio homem.

$\mathrm{Na}$ vida social moderna cada um procura se esforçar para prover com sua atividade uma porção do trabalho no projeto de vida social do outro indivíduo. Esse esforço produz um efeito desequilibrador no próprio homem dividido. O trabalho é nesse contexto um bloco dinâmico de 
atividades individuais sociais encadeada uma a uma. E o sofrimento segue a reboque desse mesmo encadeamento.

A natureza humana também não é exatamente igual. Cada ser tem suas particularidades inerentes a sua matriz criadora tanto genética quanto espiritualmente. Cada ser humano guarda em si mesmo uma configuração específica no processo de percepção do mundo. Os sentimentos, os desejos, as virtudes, os gostos e os modos de pensamentos variam de indivíduo para indivíduo e de pessoa para pessoa. A busca de uma uniformização e padronização desses elementos intrínsecos da natureza humana foi o arcabouço do projeto de vida social nas sociedades modernas.

Não podemos perder de vista que o objetivo principal era a realização social na felicidade de todas as pessoas, refletidas nas ações das liberdades individuais. Enquanto essa satisfação não fosse alcançada o projeto de vida social não estaria totalmente concluído. Assim ao longo de vários séculos um esforço de aprimoramento das formas de exercer e encadear as atividades se fez necessário. Novos métodos e metodologias foram criados de acordo com o modelo social, científico, político e econômico da época.

A organização era também nesse empreendimento um sub-projeto e como tal precisava ser administrada através de mecanismos que estabelecessem uma coesão funcional condizente com esse projeto de vida. E para se ter um sistema coeso era necessário que se criasse pontes duradouras entre as atividades. As pontes de ligação entre atividades dentro do trabalho social foram direcionadas segundo duas forças de coesão: o sentido do valor de uso e o sentido do valor de troca.

Submersa nesse oceano de pontes produtivas (sentidos de uso e troca) a vida moderna formou uma grande rede social de imensa complexidade regulada por uma abstração logicamente bem definida. As pontes foram cada vez mais crescendo e interligando nichos de interesses sociais de um número cada vez maior de comunidades. A força de coesão utilitária-econômica assegurava a continuidade do projeto social. E assim a medida que as pontes aumentavam em número, a sua força de coesão garantia a permanência de cada uma das atividades na rede montada. A entrada na rede de uma nova atividade era um processo natural. No entanto a saída de qualquer atividade já não era tão natural assim. Nesse ponto, a rede técnica-social vivia segura da sua existência eterna. E exigia a vida de cada atividade produtiva para não sucumbir na morte.

A morte é certa mas pode ser adiada se instrumentalizamos certas funções orgânicas da vida. O ser moribundo ainda pode respirar se adaptamos o seu sistema de absorção de energia. A inserção de energia na rede social foi através da crença produtivista do progresso acelerado para todas as entidades que constituíam o próprio empreendimento.

Estudos têm mostrado que o enfarte de miocárdio em executivos e profissionais que vivem sobre a pressão do ritmo produtivo é um problema gerado pela vida moderna acelerada. $\mathrm{Na}$ ânsia de não deixar o projeto social "falhar", o homem moderno abraça a sua atividade-causa que por sua vez se transforma em efeito na sua própria vida: a doença física e psíquica. Esses executivos e 
profissionais são verdadeiros nós (ou pontos críticos) do modo de produção da imensa rede sóciotécnica capitalista e como tal refletem a velocidade e a intensidade da energia que circula por essa rede. E o número de enfartes no Brasil é alto, e está crescendo, pois "uma pesquisa coordenada pelo cardiologista Leopoldo Piegas, do Hospital do Coração, em São Paulo, acaba de concluir que a freqüência de enfartes entre brasileiros com menos de 55 anos é $40 \%$ maior que a média do resto do mundo" (LUZ, 1997, p.80).

E nunca podemos esquecer que a natureza da disciplina do trabalho determina o sentido de transformação e o modo de realização. O que se planta é o que se colhe. O que se cultiva é o que vai crescer. É a ordem do universo. E é o sentido das leis. O indivíduo atuante cultiva o crescimento social a seu próprio modo, quando pensa e sente construindo modelos de sobrevivência. Mas, a natureza tem princípios que chama esse indivíduo para uma evolução calcada numa transformação de sitranscendental, num modo próprio existencial. Nesse contexto, se apresenta em cada mundo humano particular uma crise de visão e de decisão de valor: o que devo fazer? qual é o caminho certo a seguir? trabalhar para que? satisfazer a necessidade do pão? providenciar o conforto seguro da vida? ou conquistar a liberdade na felicidade do Amor? transcender ou permanecer? É nesse dilema existencial (biológico/moral e moral/ético) que todos os indivíduos modernos, sem exceção, se encontram ou já se encontraram. O estresse, a infelicidade e a constante insatisfação humana é ao mesmo tempo uma doença e um produto do modo de produção e organização social.

\section{Referências}

LUZ, Sérgio Ruíz. Perigo precoce: No Brasil, pesquisa mostra que o infarto chega mais cedo do que no resto do mundo, Revista Veja, 19/11/1997, p.80.

MELGAÇO DA SILVA, Bernardo. A força do trabalho humano e as suas dimensões ética, estética e técnica nas culturas moderna e tradicional, Tese de doutorado do Departamento de Engenharia de Produção da Universidade Federal do Rio de Janeiro, 1998. 470pp.

MOURA, Paulo Cavalcanti da Costa. O Benefício das Crises. . 2. ed. Rio de Janeiro: Mauad, 1995.

\section{Sobre o Autor:}

1. Bernardo Melgaço da Silva é Professor da Universidade Regional do Cariri - URCA/CE.

E-mail: bernardomelgaco@gmail.com 


\section{Como citar este artigo (Formato ISO):}

SILVA, B.M.. A ciência, a tecnologia, a infelicidade e o estresse humano no trabalho. Id on Line Revista de Psicologia, Fevereiro de 2013, vol.1, n.19, p. 12-18. ISSN 1981-1189. 